\title{
AVALIAÇÃO HEMATOLÓGICA E BIOQUÍMICA DE SUÍNOS DA REGIÃO METROPOLITANA DE CURITIBA
}

\author{
(Hematological and biochemical evaluation of pigs of the Metropolitan Region of Curitiba)
}

Darleny Eliane Garcia Horwat, Paula Teixeira Poltronieri, Juliana Sperotto Brum

Universidade Federal do Paraná, Curitiba, Paraná, Brasil

*Correspondência: darlenyhorwat22@gmail.com

RESUMO: Exames hematológicos e bioquímicos podem ser utilizados como auxílio para identificação de doenças e do estado nutricional de um rebanho. No entanto, para interpretar esses resultados adequadamente é necessário considerar a idade do suíno, estado fisiológico e dados clínicos, bem como histórico da propriedade. Neste trabalho objetivou-se avaliar os resultados de exames hematológicos e bioquímicos de suínos de produções de subsistência localizadas na Região Metropolitana de Curitiba. Para isso foram colhidas amostras de sangue de oito suínos, por meio da punção da veia jugular, veias da orelha ou veia coccígea. O baixo número de suínos avaliados é justificado pela dificuldade no acesso aos animais, já que em muitas propriedades eles eram mantidos soltos, a dificuldade de contenção, pois muitos não estavam acostumados ao contato, e a dificuldade da colheita de sangue nessa espécie. As amostras foram identificadas, colocadas em caixa térmica com gelo e levadas ao Laboratório de Patologia Clínica Veterinária da Universidade Federal do Paraná. No laboratório foi realizada a contagem de eritrócitos e plaquetas, contagem total e diferencial de leucócitos, hematócrito, e determinação da concentração de hemoglobina, proteína plasmática total e fibrinogênio. Com o soro foram mensurados albumina, cálcio, colesterol, fósforo, magnésio e ferro. Um dos oito suínos apresentava anemia não regenerativa, microcítica e normocrômica. A deficiência de ferro é uma causa comum de anemia nessa espécie e ocasiona anemias microcíticas. Como o nível sérico de ferro deste animal estava dentro do parâmetro, seria necessário a mensuração da ferritina e da capacidade total de ligação de ferro para confirmação desse diagnóstico (Weiss e Wardrop, 2010). Dois suínos apresentaram um leucograma indicativo de estresse crônico, com contagem de leucócitos totais dentro da referência, neutrofilia e linfopenia, e ausência de desvio à esquerda (Weiss e Wardrop, 2010). Este resultado pode estar relacionado a fatores ambientais e de manejo. Dois animais apresentaram eosinofilia, o que pode ser associados a infecções parasitárias. Todos os suínos tinham o nível sérico de colesterol acima da referência, o que possivelmente está associado ao fato das coletas terem sido feitas sem jejum prévio. O nível sério de magnésio estava abaixo da referência em todos os avaliados, o que indica uma alimentação pobre nesse mineral. A concentração sérica de magnésio tende a representar sua presença na dieta, já outros minerais, como o cálcio, não são bons indicadores do estado nutricional por manterem níveis constantes no sangue (Soto-Blanco, 2015). Observou-se também que, um suíno apresentou o nível sérico de albumina e fósforo abaixo do valor de referência, e outro o de proteína. O nível de albumina e proteína abaixo do valor de referência pode estar relacionado a dietas pobres em proteína, não sendo um resultado conclusivo. Níveis alterados de proteínas plasmáticas e albumina também podem ser relacionados com alterações na funcionalidade hepática (Soto-Blanco, 2015). Os resultados dos exames indicam que nas propriedades analisadas existem deficiências nutricionais e problemas ambientais, porém, tais indicativos só poderão ser confirmados por meio de uma avaliação mais profunda.

Palavras-chave: deficiência nutricional; sangue; subsistência.

\section{Agradecimentos}

O presente trabalho foi realizado com apoio da Coordenação de Aperfeiçoamento de Pessoal de Nível Superior - Brasil (CAPES)

\section{Nota}

O projeto que originou os dados apresentados foi aprovado pela Comissão de Ética no Uso de 
Animais do Setor de Ciências Agrárias da Universidade Federal do Paraná sob o protocolo 98/2017.

\section{Referências}

SOTO-BLANCO, B. Parâmetros sanguíneos como ferramenta zootécnica. Caderno de Ciências Agrárias, v.7, suppl, p.101-115, 24 nov. 2015.

WEISS, D.J.; WARDROP, K.J. (Eds). Schalm's veterinary hematology. 6.ed. Ames: Wiley-Blackwell, 2010, 1206p. 